http://jmscr.igmpublication.org/home/ ISSN (e)-2347-176x ISSN (p) 2455-0450

crossref DOI: https://dx.doi.org/10.18535/jmscr/v8i11.65

Journal Of Medical Science And Clinical Research

\title{
A Study of Correlation of Peradeniya Organophosphorus Scale (POP) and Serum Amylase Level in Assessing the Clinical Severity and Outcome of Organophosphorus Compound Poisoning
}

\author{
Dr Sindhu Malini.B ${ }^{1}$, Prof. Dr Ramakrishna Rao. $\mathbf{M}^{2}$, Prof. Dr Periyasamy $\mathbf{S}^{3}$
}

${ }^{1}$ Postgraduate, Department of General Medicine, Rajah Muthiah Medical College and Hospital,

Chidambaram, India, 608002

${ }^{2}$ Professor, Department of General Medicine, Rajah Muthiah Medical College and Hospital, Chidambaram, India, 608002

${ }^{3}$ Professor, Department of General Medicine, Rajah Muthiah Medical College and Hospital, Chidambaram, India, 608002

\begin{abstract}
Background: Organophosphorus compound (OPC) poisoning is common in developing countries like India. In the recent times, POP scale and serum amylase levels are being used as a marker to assess the clinical severity of OPC poisoning. In the present study, patient's clinical scoring by POP scale and serum amylase levels were estimated and its correlation with the clinical severity and outcome of OPC poisoning were established.

Aim of the study: To assess the outcome of Organophosphorus poisoning in relation to the serum amylase levels and POP (Peradeniya Organophosphorus) scale

Materials and Methods: A hospital based observational study was conducted in Rajah Muthiah Medical College from November 2018 to June 2020 in Medical Care Units. A total of 100 patients who met the selection criteria were included in the present study. At the time of admission, patient's clinical scoring using POP scale was done. At the initial presentation and after 48 hours of admission, serum amylase levels were estimated.

Statistical Methods: Statistical analysis was done using software's like SPSS version 23.0, MEDCOLC, Microsoft excel 2019.

Results: In this study, themean serum amylase level was $268.65 \mathrm{IU} / \mathrm{L}$. The mean amylase level was 282.32 IU/L in the non survivors. POP scoring and serum amylase levels correlated directly with the severity of $O P$ poisoning and mortality with a statistically significant p value of $<0.001$

Conclusion: Serum amylase level and Peradeniya organophosphorus scale (POP) correlated well with the clinical severity of OPC poisoning and are better predictors of the outcome, which were either recovery or death. Several studies on OPC poisoning were reported in the literature; however consensus is yet to be established on the role of serum amylase level and POP scale in OPC poisoning

Keywords: Organophosphorus compound $(O P C)$ poisoning, Peradeniya Organophosphorus poisoning (POP) scale, Serum Amylase, Respiratory Failure, Ventilator Support.
\end{abstract}




\section{Introduction}

Organophosphorus compounds (OPC) are most commonly used as insecticides. OPC poisoning is common in developing countries like India, where agriculture is the most common source of economy. Due to the easy and cheap availability, lack of awareness, lack of personal protective equipment, intentional and accidental poisoning with the hazardous compounds are increasing at an alarming rate in countries like India at a range of $10.3 \%$ to $43.8 \%{ }^{[1]}$.

Acetylcholinesterase (AChE), an enzyme located in the neuromuscular junction of the central and peripheral nervous system are inhibited by OP compounds. This results in increase in the acetylcholine production at the neuromuscular junction resulting in depolarization block. The presence of muscarinic and nicotinic symptoms is attributed to the increase in acetylcholine levels [2].

Serum amylase is used as a biomarker in assessing the severity of OPC poisoning in the recent times. In OPC poisoning, as a result of parasympathetic overstimulation, serum amylase levels were elevated secondary to pancreatic injury. Peradeniya Organophosphorus scale (POP) is used to assess the clinical severity of OPC poisoning ${ }^{[3]}$. In the literature, there have been studies establishing the correlation of elevated serum amylase levels with the severity of OPC poisoning and the need for ventilator support ${ }^{[4]}$.

\section{Aims and Objectives}

In this study, serum amylase levels and Peradeniya organophosphorus scale (POP) were studied to assess the clinical severity and outcome of OP compound poisoning.

\section{Materials and Methods}

\section{Study Design:}

A hospital based observational study was conducted in 100 patients in Rajah Muthiah Medical College (RMMCH), Chidambaram, Tamil Nadu, from November 2018 to September 2020, admitted with alleged history of
Organophosphorus

compound

poisoning in

Medical Care Units

\section{Selection of Patients}

\section{a. Inclusion Criteria}

Patients who got admitted in Medical Care Units with suspicion of or with provisional diagnosis of or with history of consumption of OPC poisoning, serum cholinesterase levels were estimated and whose levels are less than 4900 IU/L, were included in the present study.

\section{b. Exclusion Criteria}

1. Patients who received initial treatment in hospitals other than RMMCH.

2. Patients who received treatment with atropine before admission

3. Patients with serum cholinesterase level above $4900 \mathrm{IU} / \mathrm{L}$.

4. Patients with history of poisoning with other drugs such as opioids, diazepam, barbiturate.

5. Patients with history of neuromuscular diseases like myasthenia gravis, muscular dystrophy were excluded from the present study.

The patients who met the selection criteria were enrolled into the study after obtaining informed written consent. Based on a preformatted proforma, detailed history, clinical examination, relevant biochemical investigations were obtained from the selected patients.

At the time of presentation, POP scale (Table 1) was used to assess the patient's clinical severity and was categorized as mild, moderate and severe poisoning based on the POP score. 
Table 1: Peradeniya Organophosphorus Scale (POP)

\begin{tabular}{|c|c|c|c|}
\hline S.No & Parameter & Score & Patient's score \\
\hline \multirow{4}{*}{ I. } & Pupil Size & & \\
\hline & $>2 \mathrm{~mm}$ & 0 & \\
\hline & $<2 \mathrm{~mm}$ & 1 & \\
\hline & Pinpoint & 2 & \\
\hline \multirow{4}{*}{ II. } & Respiration & & \\
\hline & $\mathrm{RR}<20 \mathrm{mins}$ & 0 & \\
\hline & $\mathrm{RR}>20 / \mathrm{min}$ & 1 & \\
\hline & RR>20/min with central cyanosis & 2 & \\
\hline \multirow{4}{*}{ III. } & Bradycardia & & \\
\hline & $\mathrm{HR}>60 / \mathrm{min}$ & 0 & \\
\hline & HR 41 to $60 / \mathrm{min}$ & 1 & \\
\hline & $\mathrm{HR}<40 / \mathrm{min}$ & 2 & \\
\hline \multirow{4}{*}{ IV. } & Fasiculations & & \\
\hline & None & 0 & \\
\hline & Present, generalized or continuous & 1 & \\
\hline & Both, generalized and continuous & 2 & \\
\hline \multirow{4}{*}{ V. } & Level of Consciousness & & \\
\hline & Conscious and rationale & 0 & \\
\hline & Impaired response to oral commands & 1 & \\
\hline & No response to oral commands & 2 & \\
\hline \multirow{3}{*}{ VI. } & Seizures & & \\
\hline & Present & 0 & \\
\hline & Absent & 1 & \\
\hline
\end{tabular}

Table 2: Grades of Peradeniya Organophosphorus Scale (POP)

\begin{tabular}{|c|c|}
\hline Grade & Pop score \\
\hline Mild & 0 to 3 \\
\hline Moderate & 4 to 7 \\
\hline Severe & 8 to 11 \\
\hline
\end{tabular}

\section{Sample Collection}

About $3 \mathrm{ml}$ of venous blood was taken from the selected patients and was centrifuged at 3000rpm for 15 minutes and serum amylase level was estimated by an autoanalyzer using CNPG3 method. The correlation of the patient's clinical POP scoring, serum amylase level and the outcome of OP compound poisoning were established by statistical analysis.

\section{Results}

In this study of 100 consecutive cases of our study population, about $59 \%$ patients were males and $41 \%$ of them were females. Majority of them belonged to the age group of 20 to 40 years as depicted in the figure 1 .

Figure 1: Age and Gender distribution $(\mathrm{N}=100)$

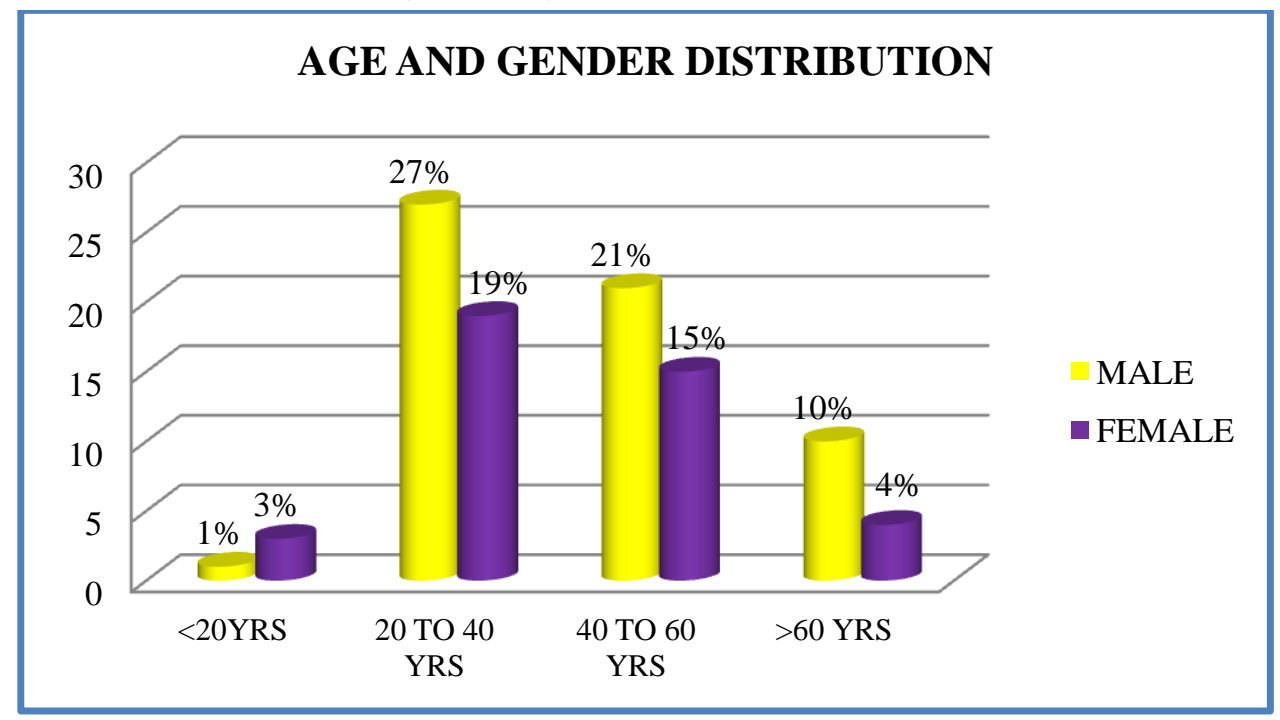




\section{JMSCR Vol||08||Issue||11||Page 377-384||November}

Figure 2: Agent of poisoning $(\mathrm{N}=100)$

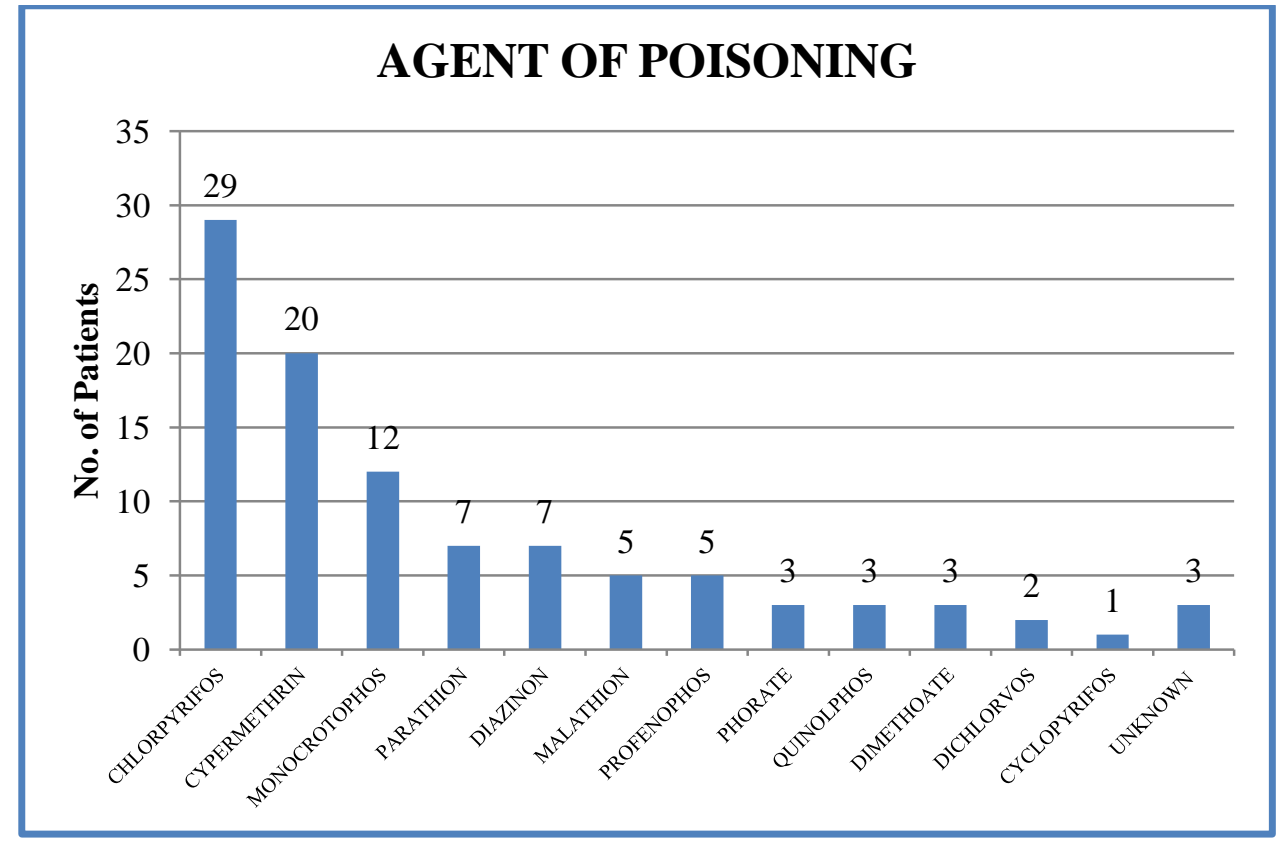

The agents used for poisoning in decreasing order of frequency includes chlorpyrifos (29\%), cypermethrin (20\%), monocrotophos (12\%), parathion $(7 \%)$ and other OP compounds as shown in the figure 2 as depicted above.
In our study, about $49 \%$ patients presented with mild poisoning whereas about $13 \%$ patients reported with severe poisoning according to the POP scale as described in the figure 3.

Figure 3: Distribution of patients based on POP score $(\mathrm{N}=100)$

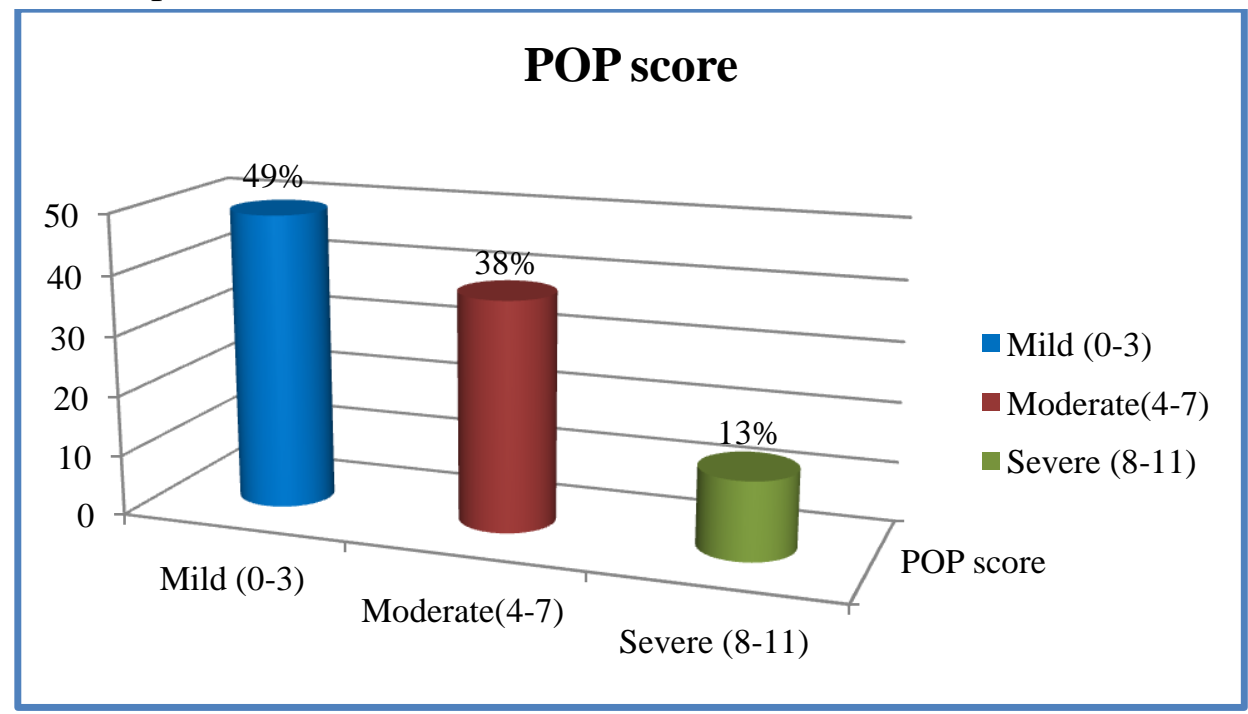

Table 3: Distribution of patients based on serum amylase elevation at the time of admission $(\mathrm{N}=100)$

\begin{tabular}{|l|c|c|}
\hline Serum amylase 1 & No. of patients & Percentage \\
\hline Mild $(<150)$ & 13 & $13 \%$ \\
\hline Moderate $(151$ TO 400$)$ & 72 & $72 \%$ \\
\hline Severe $(>401)$ & 15 & $15 \%$ \\
\hline
\end{tabular}

Table 3 and 4 shows the distribution of patients based on the elevations in serum amylase levels at the time of initial presentation and after 48 hours of admission respectively. 
Table 4: Distribution of patients based on serum amylase elevation after 48 hours of admission $(\mathrm{N}=100)$

\begin{tabular}{|l|c|c|}
\hline Serum amylase 2 & No. of patients & Percentage \\
\hline Mild $(<150)$ & 47 & $47 \%$ \\
\hline Moderate (151 TO 400) & 51 & $51 \%$ \\
\hline Severe (>401) & 2 & $2 \%$ \\
\hline
\end{tabular}

In our study, by comparing the tables 3 and 4, there is a significant fall in serum amylase levels
48 hours after admission compared to the initial amylase levels.

Figure 4: Distribution of patients based on ventilator support $(\mathrm{N}=100)$

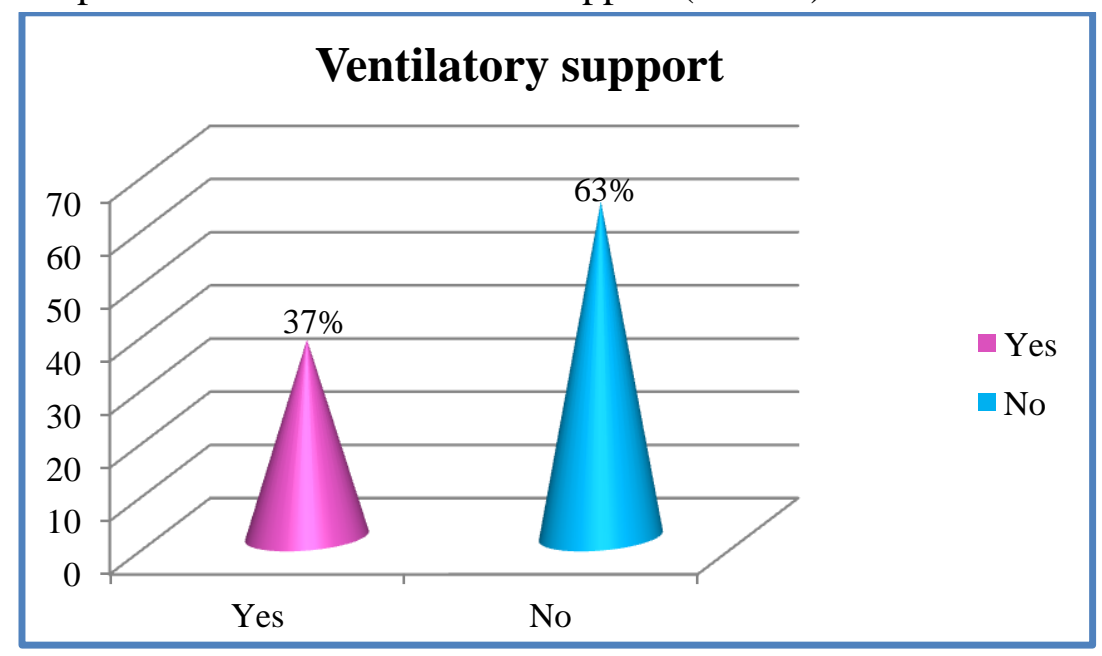

In our study, about $37 \%$ of patients developed respiratory failure and were connected to mechanical ventilator. Among them, $17 \%$ of patients expired. In this study, the overall mortality was about $17 \%$ as depicted in the figure 5 .

Figure 5: Outcome of OPC poisoning patients $(\mathrm{N}=100)$

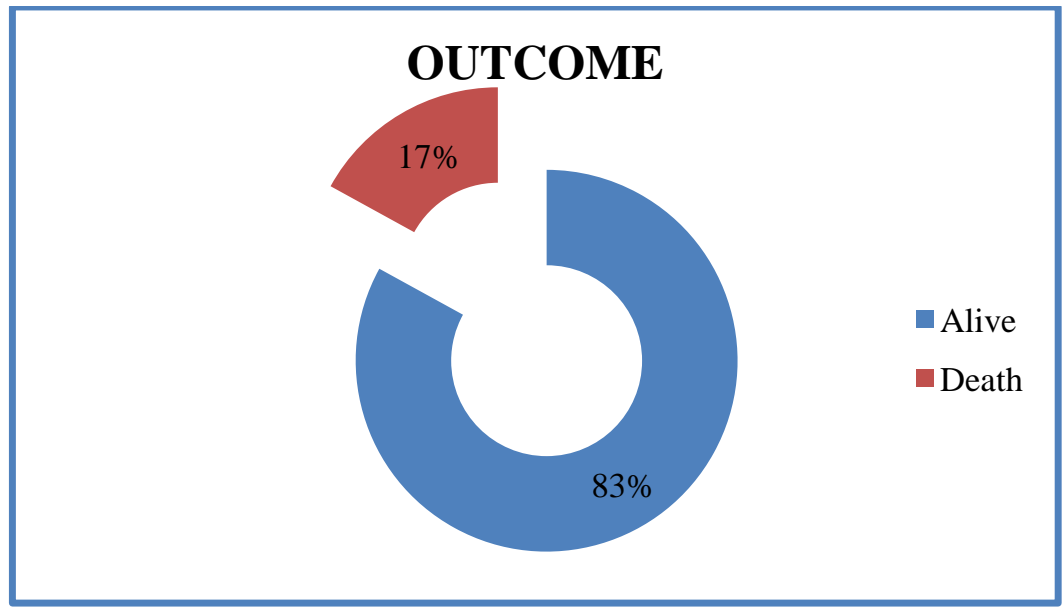

Table 5: Serum Amylase level versus outcome

\begin{tabular}{|l|c|c|c|}
\hline \multirow{2}{*}{ Serum amylase } & \multicolumn{2}{|c|}{ Outcome } & \multirow{2}{*}{ Total } \\
\cline { 2 - 3 } & Alive & Death & \\
\hline Mild( <150) & 13 & 0 & 13 \\
\hline Moderate (151 to 400) & 64 & 8 & 72 \\
\hline Severe (>401) & 6 & 9 & 15 \\
\hline Percentage & $83 \%$ & $17 \%$ & $100 \%$ \\
\hline Pearson Chi Square & 24.089 & P Value & $<0.001$ \\
\hline
\end{tabular}


From the table 5, it was concluded that among 15 patients with severe hyperamylasemia at the time of presentation, about 9 patients died and 6 patients survived with the Pearson chi square value of 24.089 and with the $\mathrm{P}$ value of $<0.001$ which was statistically significant.

Table 6: Serum amylase level at the time of initial presentation versus ventilator support

\begin{tabular}{|l|c|c|c|}
\hline \multirow{2}{*}{ Serum amylase } & \multicolumn{2}{|c|}{ Ventilator support } & \multirow{2}{*}{ Total } \\
\cline { 2 - 3 } & Yes & No & \\
\hline Mild (<150) & 0 & 13 & 13 \\
\hline Moderate (151 to 400) & 21 & 51 & 72 \\
\hline Severe (>401) & 15 & 0 & 15 \\
\hline Percentage & $36 \%$ & $64 \%$ & $100 \%$ \\
\hline Pearson Chi Square & 35.819 & P Value & $<0.001$ \\
\hline
\end{tabular}

In the study, among 15 patients with severe elevation in serum amylase levels at the time of initial presentation developed respiratory failure and were on ventilator support. Table 6 with $p$ value of $<0.001$ and chi square of 35.819 shows that severe hyperamylasemia at initial presentation is associated with increased incidence of clinical severity.

Figure 6: POP score versus outcome

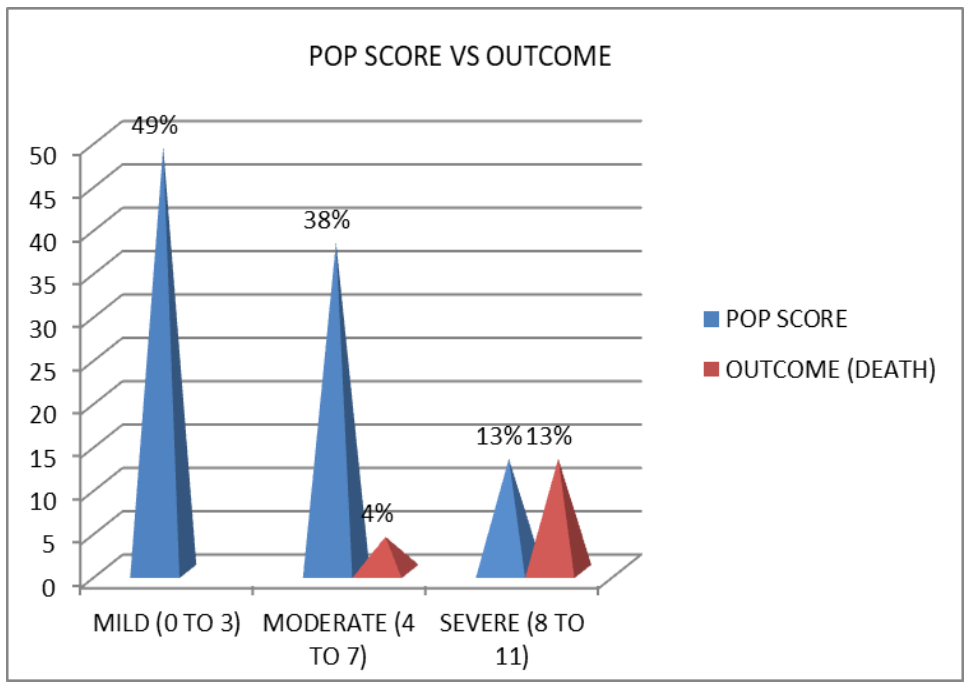

From the figure 6 , it was concluded that in the patients with severe poisoning according to POP scale, mortality rate was found to be higher.

\section{Discussion}

A comprehensive analysis of observations made from a total of 100 cases studied at RMMCH was compared with other Indian and foreign studies as follows.

In this study of 100 cases, about 59\% patients were males and $41 \%$ of them were females. Majority of them belonged to the age group of 20 to 40 years. These data were found to be consistent with similar studies conducted by Dalal et al (males were about 63\%) ${ }^{[6],}$ Agarval et al (males were about 72\%), Shalini et al (age group 25 to $40 \mathrm{yrs})^{[5]}$, Reihman et al (15 to $25 \mathrm{yrs}$ ). ${ }^{[9]}$

The agents used for poisoning in decreasing order of frequency includes chlorpyrifos (29\%), cypermethrin (20\%), monocrotophos (12\%), parathion $(7 \%)$ and these data were consistent with studies conducted by Kiran Shivaraj et al ${ }^{[10]}$ (2013) in which the incidence of chlorpyrifos was about $22 \%$. Shalini et al ${ }^{[5]}$ study reported about $13 \%$ patients who had consumed monocrotophos. Majority of patients reported with mild $(\mathrm{N}=49)$ to moderate $(\mathrm{N}=38)$ severity of $\mathrm{OP}$ compound poisoning according to POP scale and $13 \%$ patients reported with severe poisoning. This was comparable with the study conducted by Shalini et 
al $^{[5]}$ in which $62 \%$ of patients reported with mild poisoning, Arup Kumar Kundu et al, 19.5\% presented with mild poisoning followed by $50.9 \%$ patients with moderate poisoning.

In the present study, mortality was about $17 \%$ of patients. This observation was found to be consistent with the studies conducted by Manoj et $\mathrm{al}^{[11]}$ (deaths of about $17 \%$ ), Manimala et $\mathrm{al}^{[12]}$ (deaths of about 13.79\%), Kabrawala et al (deaths of about $12 \%$ ).

The most common cause of mortality in OP compound poisoning is respiratory failure. Among 100 patients in our study, 37\% of patients developed respiratory distress and this data was found to be consistent with the study conducted by Sivashankar et $\mathrm{al}^{[13]}$ (2012), in which out of 62 patients, 23 cases developed respiratory depression $(37.1 \%)$,

In this study, with $\mathrm{p}<0.05$ as significant, the statistical analysis showed a significant correlation of serum amylase level with the outcome of OPC poisoning. There was a significant fall in serum amylase level from the initial value, after 48hours following treatment. Patients with severe hyperamylasemia at the time of presentation went into respiratory failure and were in need of ventilator support. The highest serum amylase level at the time of initial presentation was 550 IU/L while the lowest level of serum amylase was $115 \mathrm{IU} / \mathrm{L}$. The mean value of serum amylase level at the time of admission was 268.65 IU/L. In comparison with the study conducted by Sivashankar et al ${ }^{[13]}$ (2012) $51.6 \%$ of patients had hyperamylasemia and there was also significant correlation with the severity of OPC poisoning. It has been reported that about $36 \%$ patients had hyperamylasemia in a study conducted by Lee et al, and it was also found to be correlating with the clinical severity of OP compound poisoning. According to Singh et al, incidence of hyperamylasemia has been reported as $46.95 \%$.

POP scoring and serum amylase levels correlated directly with the severity of OP poisoning and outcome.

\section{Conclusion}

Peradeniya organophosphorus (POP) scale and serum amylase level correlated well with clinical severity of OPC poisoning and outcome.

\section{Limitations}

This study was limited to a small population due to financial, laboratory constraints. Hence, to establish further relationship between serum amylase level, POP scale with the clinical severity and outcome of OP compound poisoning, analysis of a larger population and many further studies are needed.

\section{Conflicts of Interest}

All authors declare that we don't have actual or potential financial interest or conflict of interest

\section{Ethical Consideration}

Approval for this study was obtained from Institutional Ethical Committee of Rajah Muthiah Medical College Hospital, Annamalai University, Chidambaram, Tamil Nadu.

\section{References}

1. Gururaj G, Issac MK, Epidemiology of suicide in Bangalore, NIMHANs publication no. 43, Bangalore 2001.

2. Nandi DN, Mukherjee Sp, Banarjee G, et al. Is suicide preventable by restricting the availability of lethal agents? A rural survey of West Bengal, Indian Journal of Psychiatry 1979.

3. Senanayake N, de Silva HJ, Karalliedde L. A scale to assess severity in organophosphorus intoxication: POP scale. Human Exp Toxicology 1993;12:297-9.

4. Matsumiya $N$, tanaka $M$, Iwai $M$, et al, Elevated amylase is related to the development of respiratory failure in organophosphate poisoning, Human ExpToxicol.1996 ; 1593): 250 -253

5. Shalini et al. Correlation of POP scale and serum cholineseterase level in assessing the clinical severity and outcome of 
organophosphorus compound poisoning. 2016.ID 146077260

6. Dalal et al, "Poisoning trends: A postmortem study", Journal of Indian Academy of Forensic Medicine,1998; 20, No. 2: 27- 31.

7. Clinical management of poisoning and drug over dosage - pesticides 3rd edition W.B. Saunders; 1998:838-845.

8. Sullivan JB and Blose J. Organophosphate and carbamate insecticides. In: Sullivan JB and Krieger GR (eds), Hazardous Materials Toxicology. Baltimore, MD: Williams and Wilkins, 1992, pp. 1015-26.

9. Aaron C K, Howland M A. Insecticide: Organophosphates and Carbamates. Goldfrank Toxicological Emergencies, Gold frank L.R., Flomenbaum NE et al, 6th edition, Appleton and Lange, 1998,1429-1449

10. Kiran Shivraj, A Study on myocardial injury in organophosphorus poisoning, 2013

11. Sussman JL, Harel M, Frolow F, Oefner C, Goldman A, Toker L, Silman I (August 1991). "Atomic structure of acetylcholinesterase from Torpedo californica: a prototypic acetylcholinebinding protein". Science 253 (5022): 872-9. doi:10.1126/science.1678899. PMID 1678899

12. Manimala, "Organophosphate poisoning and its neurological manifestations", International Journal of Advances in Case Reports, 2015; 2(21).

13. Sivashankar et al, a study on the serum amylase in acute organophosphorus poisoning 2012. 